\title{
THE DEVELOPMENT, IMPLEMENTATION, AND EVALUATION OF A PROBLEM SOLVING HEURISTIC
}

\begin{abstract}
Problem-solving is one of the main goals in science teaching and is something many students find difficult. This research reports on the development, implementation and evaluation of a problem-solving heuristic. This heuristic intends to help students to understand the steps involved in problem solving (metacognitive tool), and to provide them with an organized approach to tackling problems in a systematic way. This approach guides students by means of logical reasoning to make a qualitative representation of the solution of a problem before undertaking calculations, using a 'backwards strategy,' which thus comprises a cognitive tool. The findings of the study suggest that students found the heuristic useful in setting up and solving quantitative chemical problems, and helped them to understand the phases of the problem solving process. Possible applications of the heuristic in the classroom include its use in formative assessment, to identify and to overcome student alternative conceptions, problem-solving in a cooperative environment, and to reduce the gender gap in science.
\end{abstract}

KEY WORDS: backwards strategy, cooperative learning, formative assessment, gender gap, heuristic, misconception, problem-solving, qualitative representation

Problem-solving plays a crucial role in the science curriculum and instruction in most countries, and is reported by many authors as a very difficult task for students (see, e.g., Mettes, Pilot, Roossink \& Kramers-Pals, 1980). Most of the physics and chemistry problems students are asked to solve at the high school level are quantitative problems that require knowledge of formulae and the application of mathematics. Despite numerous efforts to increase students' problem-solving abilities, many still fail to solving problems even when they are simply required to apply an algorithm in order to obtain the 'correct' solution. As a consequence, improving students' problem-solving skills continues to be a major goal of science teachers and science education researchers.

Using Hayes' (1981) definition of a problem: Whenever there is a gap between where you are now and where you want to be, and you don't know how to find a way to cross that gap, you have a problem, Bodner (1987) points out that the difference between a problem and an exercise is that if one knows what to do when one reads a question, it isn't a problem, it's an exercise. According to Bodner then, for a question to be categorized as a problem or as an exercise, there must be cognitive features (i.e., domain and general knowledge and cognitive skills) possessed by the person who 
seeks to answer the question. It is clearly important to take such issues into account in trying to teach students how to become effective problemsolvers and teachers need to be aware that most questions in the science classroom that are 'exercises' for teachers constitute difficult 'problems' for most students. Kramers-Pals, Lambrechts and Wolff (1983) suggest that for an expert, a 'problem' is not a real problem but a standard problem for which a problem-solving routine is applied. Partly for this reason many educators, being experts, mentally engage in a variety of problem-solving steps and because of this, they unconsciously fail to teach students all the reasoning and steps involved in problem-solving, especially steps related to the planning and checking stages that are essential in solving a problem (Kramers-Pals \& Pilot, 1988). However, some studies suggest that success in problem-solving depends on a combination of strong domain knowledge, knowledge of problem-solving strategies, and confidence (Ashmore, Frazer \& Cassey, 1979; Kramers-Pals \& Pilot, 1988).

The literature thus suggests that in order to increase students' problemsolving abilities, in addition to working on student understanding of key ideas (i.e., concepts, laws and formulae) related to the problem in order to increase conceptual understanding, it is necessary to teach students an organized problem-solving approach that explicitly shows them all the steps involved in the problem-solving process to help them address new problems in a systematic manner. There is reason to believe that an increase in students' conceptual and procedural knowledge will benefit their attitude and confidence towards problem-solving tasks, and therefore, to improve their problem-solving proficiency.

It seems that developing problem-solving skills in students via traditional means is not particularly successful, hence it is of interest to develop and evaluate alternative methods for teaching students problem-solving skills.

\section{Problem Solving Strategies in Chemical Education}

There are extensive reviews about problem-solving reported by Gabel and Bunce (1994) in chemistry, and in physics by Maloney (1994). Since the 1950s, there has been increased interest in developing general approaches to explain the phases that expert problem-solvers use (see, e.g., Ausubel \& Robinson, 1971; Mettes et al., 1980, 1981; Reif, 1983; Gagne, 1985; Kramers-Pals \& Pilot, 1988; Lee \& Fensham, 1996; McCalla, 2003). Many problem-solving approaches in current use are based on Polya's (1957) framework which involves four phases: understanding, planning, carrying out the plan, and looking back. Many of the problem-solving approaches 
found in the literature were developed to enable students to solve word problems, especially mathematical problems.

Much prior research into expert problem-solving processes was based on information-processing psychology (Newell \& Simon, 1972), and focused on cognitive analyses of problem-solvers' strategies, often comparing experts and novices. The following themes emerge from this body of research:

- Experts usually used a 'working forward' approach (i.e., from the data to the unknown), doing calculations from the given information in the problem statement until the unknown value is reached. While novices use a 'working backward' approach (from the unknown to the data), this strategy is an example of means-ends analysis, in which experts identify the goal, compare and find differences between the goal and the given information, and make different attempts to carry out calculations that reduce these differences until the unknown is found out (Simon \& Simon, 1978).

- Experts conduct a qualitative analysis before starting any calculations and use this analysis to construct an appropriate qualitative representation of the problem in order to identify the relevant quantities and provide a pathway to guide them (Larkin, 1983). Experts move from the original description of the problem to a qualitative description and then to a mathematical description while novices typically go from the original description directly to a mathematical description (Larkin \& Reif, 1979), without carrying out the necessary qualitative analysis needed to construct an appropriate representation (Finegold \& Mass, 1985; McMillan \& Swadener, 1991).

- Experts spend relatively more time on translation and planning, and complete the solution to a problem in less time than novices (McMillan \& Swadener, 1991).

- Experts have a cognitive structure more complex and more developed than that of novices (Kempa \& Nicholls, 1983).

In more recent work, Heyworth (1999) found means-ends analysis to be used more by novices in their problem-solving approaches than the formula-driven processes reported in earlier research. He found a gradual shift in the representations and strategies used as student expertise increases, from a primitive working-forwards strategy without a qualitative representation of the problem, to a means-ends analysis strategy with a partly or fully formed qualitative representation - finally resulting in a working-forwards strategy achieved by an expert in which all three representations are present. Heyworth suggests that a qualitative representation of a problem can be set up when a backwards strategy is used. Teachers, 
being familiar with a problem, usually use a working forwards approach when teaching how to solve a problem. But for the students, when a problem is unfamiliar, mean-ends analysis is the strategy employed initially. Hence, teachers may help students by focusing on the goal of a problem and helping them to set up appropriate sub-goals in order to develop the qualitative procedure.

Constructivist-based learning, including approaches to problem-solving (Fensham, Gunstone \& White, 1994; Hand \& Prain, 1995), imply that learners need to take a more active role in determining which problems should be addressed and in constructing their understandings of how these problems can be solved rather than following teachers' advice passively. This viewpoint extends the scope of problem-solving skills beyond calculating 'correct' answers to the development of new kinds of reasoning and thinking. As Gagne (1985, pp. 178-179) notes, problem-solving is about 'new learning,' where learners develop a higher-order rule, which becomes a part of the individual's repertoire rather than just applying previously learnt rules.

\section{ReSEARCH Methods}

The research reported here is a case study that aimed to develop, implement in a real classroom, and evaluate the effectiveness of, a problem solving heuristic (PSH) (Figure 1). The study was conducted with an intact Year-11 chemistry class (age range 16-17 years) in Spain.

\section{Development of the Problem Solving Heuristic (PSH)}

The problem solving heuristic (PSH) was initially developed in New Zealand at the end of the academic 2002 teaching year, as a result of an inquiry (based on qualitative and quantitative methods) that involved the trial of the NZ heuristic that used the same steps as the PSH reported in detail in the present work but using writing activities (i.e., the students had to write down all the steps). Here the students had to write down step 6 of the NZ heuristic in the form of a backwards pathway (Figure 2) that related the unknown to the data. The NZ study was conducted with 12 Year-11 chemistry students (age range 16-17 years) and as a first step the students were asked to solve a chemistry problem where they had to determine the empirical and molecular formulae of an organic compound without using the heuristic. After this, they were told how to use the heuristic with the researcher explaining each step of the heuristic and illustrating the process by solving 


\section{PROBLEM SOLVING HEURISTIC}

1. Read the problem carefully.

2. Look up in textbooks or dictionary the meaning of the words you don't know.

3 . Identify what the problem is about, be as specific as you can.

4. Identify the unknown and the data.

5. Determine what kind of quantities the unknown and the data are.

6. Express all the quantities in the same unit system.

7. Organize the information in the problem statement using a drawing, a diagram, a flow chart, a graph or whatever representation that may help you to understand better the problem situation.

8. Make a "map" that shows the relationships between the unknown and the data (from the unknown to the data). In order to do that write down the quantities of the unknown and the data at the top of the map (unknown on the left and data on the right side) with their corresponding amounts and units (see the example in Figure 3). Do you know how these quantities are related?

- If yes, use your ideas to solve the problem.

- If no, break your problem into parts.

9. Break the problem into parts:

In order to do that, look for the relevant ideas (definition, formulae related with it, information you can get from it) related with the unknown and write down in the map the quantities related with it. Connect the unknown and the quantities related with it through arrows and write down, on the right side, the formulae o conceptual thinking that related these quantities, as in the example. Write down the values (close to their corresponding quantities) you know for these quantities.

- If you have the values of all the quantities related with the unknown, use the relationship (formulae or qualitative thinking) between them to solve the problem.

- If you do not know the values for some of these quantities then you have a new unknown or unknowns (write down a question mark close to these quantities), hence you have a new problem or problems. So you have to look for a relationship between the new unknown or unknowns and the data.

In this step it can be helpful to compare this problem with the ones, even in other topics, you have solved before and you think are similar or related to.

Repeat this process until you know values for all the quantities related with the last unknown.

If you got in different branches of the same map, the same quantity and you do not know its value you can assume an arbitrary value for this quantity and then solve the problem.

10. Once you know the pathway that related the unknown to the data, the problem is qualitatively solved, then to solve it quantitatively you have to apply the calculations from the data to the unknown (from the bottom to the top) using the formulae or conceptual thinking written on the right side. Be careful with calculations and units.

11. Check if your answer is reasonable. If not review the previous steps

12. Write down the ideas you have learnt in doing this problem.

Figure 1. Problem solving heuristic. 
STEP 6. Think how the unknown and the data are related and try to make a scheme that shows this relationship. Write down:

(a) I have to find out the (write the problem question):

(b) So I have to look for a relationship between (write down the quantities of the unknown and data in the problem question):

(c) Use the ideas in the previous steps and compare this problem with other similar problems. Do you know how these quantities are related?

- If yes, go to step (g), and use your ideas to solve the problem in step (7).

- If no, break your problem into parts.

(d) (Breaking the problem into parts). The (write the unknown) is related to

(e) As I know the value(s) for (write down the values you know for the quantity or quantities above written):

now my new problem is to find out (write down the problem question changing the initial unknown for the quantity or quantities you don't know values for it/them):

so I have to look for a relationship between the above quantities.

(f) Use the ideas in the previous steps and compare your new problem with other similar problems. Do you know how these quantities are related?

- If yes, go to step (g), and use your ideas to solve the problem in step (7).

- If no, break your problem into parts and repeat the steps from (d) to (f) until you find a relationship between the last unknown and the data question.

(g) Write down a possible pathway, from the unknown to the data, that relate all the quantities in the previous steps.

Unknown $\longleftrightarrow$ quantity $\mathrm{A} \longleftrightarrow$ quantity $\mathrm{B} \longleftrightarrow \cdots \longleftrightarrow$ data question

Figure 2. Step six of the NZ problem solving heuristic. 
two chemistry problems about stoichiometry and solutions that were different from the task set the students. Next, the students were asked to solve the formulae problem again but this time using the NZ heuristic. The findings showed statistically significant gains $(p$-value $=0.0358)$ in the NZ students' problem-solving performance when using the heuristic. A note of caution is required however in that only two students $(16.66 \%)$ solved the problem without using the heuristic, but seven students (58.33\%) found the solution using the heuristic. However, the analysis is indicative that the heuristic may prove helpful in enhancing student problem-solving skills. In addition evaluation of the pilot study found that the students thought the heuristic useful but very time-consuming. Consequently, before using the heuristic in the present work (i.e., in Spain) the NZ heuristic was redrafted as it appears in Figure 1 to make it easier to use and less time-consuming.

The development of the PSH used in the present work was based on the following hypotheses:

- The problem-solving process involves four phases: understanding, planning, carrying out the plan and looking back (Polya, 1957);

- A backwards approach is used to help set up a qualitative representation to solve the problem (Heyworth, 1999);

- Learning is an active process where new knowledge is incorporated into what the learner already knows (Ausubel, 1968);

- Problem solving is a process that uses prior knowledge and produces new learning (Gagne, 1985).

The PSH intends to help students understand the phases involved in problem-solving (metacognitive tool) and to provide them with an organized approach to tackling problems in a systematic way, to increase their cognitive skills (procedural knowledge) (cognitive tool) which then results in increased domain knowledge.

The heuristic model presented here pays particular attention to the different quantities rather than to numerical values. Students have to identify the kinds of quantities that the unknown and the data are (step 5) and to seek the relationships between them (steps 8 and 9) using a pathway similar to that proposed by McCalla (2003). They then have to work on the quantities to develop the conceptual understanding needed to construct a qualitative representation of the problem before engaging in calculations. This is an important feature of a constructivist-based approach since through this model teachers can focus on the relationship between different quantities that are involved in the solution and in this way help build the cognitive structure of the students. The intention is that the students' conceptual knowledge will be increased as well as their procedural problem-solving skills. The value of this model is that it is intended to work 
on the conceptual reasoning to make a qualitative representation of the problem and this process is intended to reduce the gap between conceptual understanding and an algorithm approach.

In addition to this constructivist-based approach, the framework presented here adds a new stage to Polya's (1957) approach, a stage called the 'learning stage' (step 12) where the students have make a conscious effort to determine what they have learnt by doing the problem. This enables them to check changes to their knowledge structures, and affords possible generalizations and reflections on the total process of problem-solving. As Gagne (1985) suggests, problem-solving is a process that uses previous knowledge and at the same time produces new learning. This is a key feature of the PSH presented here.

The PSH can be used in whatever manner the learner wishes in terms of progression through the steps, consistent with a learner-centered constructivist-based approach; in other words it need not be viewed as a linear process. Indeed, the map format allows students to easily pass from one of Polya's (1957) steps to another during all stages of the problem-solving process.

Finally the PSH can be applied not only to quantitative problems but also to qualitative questions and potentially to other subjects different from chemistry.

\section{ImPlementation OF THE Problem Solving Heuristic IN THE ClASSROOM}

The heuristic is illustrated by some sample problems. It is convenient to begin with easy problems and then to move to more difficult ones. This way the students can understand easily how the heuristic works, and come to appreciate the difference between an exercise and a problem, and the heuristic's value in solving difficult problems.

To begin by explaining the heuristic, a copy of the PSH is given to each student along with some examples of problems solved using this model (Figure 3). The teacher then explains the main purpose of each step and the process of using the heuristic by solving some sample problems following the model.

It is helpful to begin working on the problem statement, writing it on the blackboard or by using a transparency. In order to help students understand step 2, where they have to look up the meaning of the words they do not know, it is convenient to choose a problem statement with some words that are unfamiliar or difficult for the students. At step 3, the students have to identify what the problem is about, hence at this stage it is important 
PROBLEM SOLVING HEURISTIC

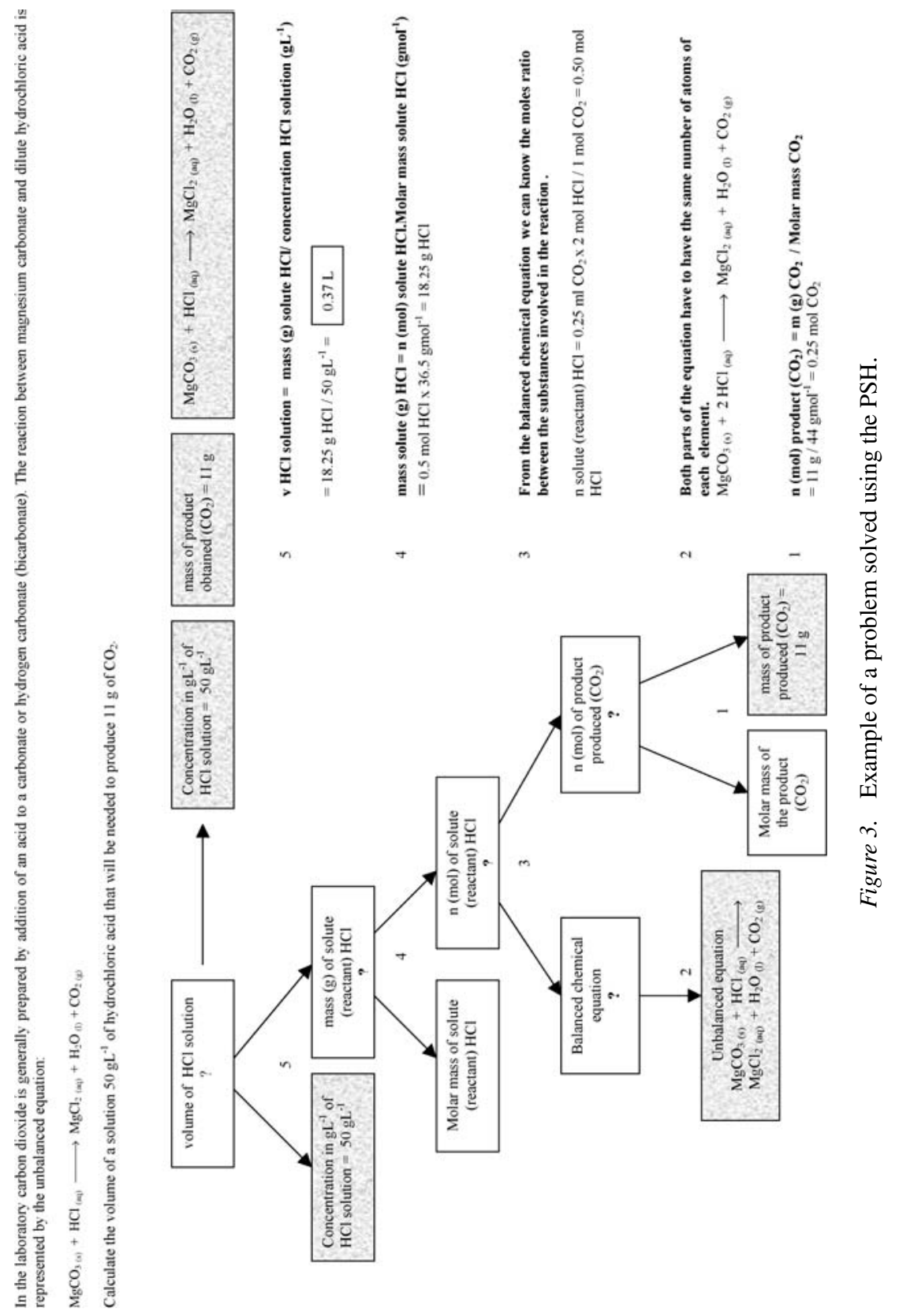


to emphasize to the students that they have to be as specific as possible when describing what the problem is about. The more specific they are the easier it is for them to select the appropriate key relations needed to solve the problem. In step four, where students have to identify the unknown and the data, it is useful to underline the unknown and the data in the problem statement - different colors can be used on a transparency for the unknown and the data once the students have identified them. After students have identified the kind of quantities that the unknown and data are, it is time-saving to write the magnitudes of the quantities on the top of the blackboard or transparency, with say the unknown on the left and data on the right. In this way this information does not have to be rewritten again in step eight, where the 'problem map' has to be constructed. In step 7, where students have to organize the problem statement information by producing some kind of representation, it is convenient for the teacher to look at the different students' representations moving around the class, making some comments about the different ways students have represented the problem, and put one representation on the blackboard to help represent the problem at the macroscopic level. When doing exercises about the same topic it saves time to have a transparency showing the key relationships. It is important to add to this transparency the ideas obtained in the last step, where the students have to write down what they have learnt by doing the problem. This helps to show students that their knowledge in problem-solving has increased by solving specific problems and this increases their confidence. After completing the calculations, the teacher needs to emphasize the idea that the aim of doing a problem is to increase the solvers' knowledge (step 12), only then should the teacher ask students to think about and write down what they have learnt in doing this problem.

\section{Evaluation of the Value of the Problem Solving Heuristic}

The PSH presented in this work is based on a sound theoretical base derived from the literature. However, with any intervention it is important to consider if the intervention has indeed enhanced student learning in any way. Hence the author conducted an evaluation of the PSH in order to asses its effectiveness, together with the students' views as to the best and worst features of the heuristic. In order to evaluate the value of the heuristic it was used with an intact class of 17 Year-11 chemistry students (age range 16-17 years) at a large high school in Spain at the beginning of the second term of the academic year for 2003. The sample consisted of 2 girls and 15 boys. These students were enrolled in the first year of 'technological studies.' In this class, students are required to study chemistry until the 
end of February and then physics. They have to attend four 50-minute periods each week. The chemistry background of the students was fairly limited with the students having only studied solution chemistry two years ago and then very briefly. To illustrate their background the students had only studied how to express the concentration of a solution in $\mathrm{g} / \mathrm{L}$ and percentage mass. They had not, for example, studied the mole concept until the beginning of the year in which the heuristic was administered. The instruction method used by their teachers before the use of the heuristic is best described as traditional - being rather didactic in nature.

As one of the aims of this study was to evaluate the PSH, the students of this group were asked to solve two chemistry problems in solution chemistry. They were asked to solve the problems in a qualitative way, by only constructing the 'problem map' and they did not have to produce a numerical answer. The purpose of only asking student to make a 'map' of the problems was to see if they were able to construct a map for a given problem in order to check if they had understood how to do the map. The intention here was to get feedback from the students about the value of the PSH rather than to do a quantitative study on student achievement using the heuristic. In order to do such study it would be necessary to use the PSH for a longer period of time and to use a control group.

The students were advised that they could use their textbooks, notebooks, or any other sources of information they wished in order to solve the problems - but they had to do the tasks by themselves. The problems were applied to chemical solutions because it was the topic students were studying at the time the research was conducted. The teacher had addressed the concepts of solutions and different ways to expressing the concentration of a solution but only a few word problems were done before this study was carried out. As indicated above, the heuristic was modeled to the students before they attempted to use it themselves. The researcher conducted a demonstration in which four problems were solved, in increasing order of difficulty.

The students took about 15 minutes to solve each problem, although three students spent more time on the first problem and one student did not have enough time to complete the second problem. After solving the two problems, the students were asked to complete an open-ended questionnaire designed to seek feedback on the usefulness of the PSH. It was assumed that listening to what students who use the PSH have to say about their experiences as PSH users would serve as a way of evaluating the validity of the heuristic. 


\section{Problem ANSWERS AND ANALYSIS}

The first problem $(20 \mathrm{~mL}$ of $2 \mathrm{~mol} / \mathrm{L} \mathrm{KOH}$ is diluted to $1 \mathrm{~L}$. Calculate the new concentration of $\mathrm{KOH}$ ) was answered correctly by 10 students $(59 \%)$. An example of a student's work is showed in Figure 4. Five of the students (29\%) managed to produce all the correct quantities and relationships, their maps were well constructed, but they misunderstood the meaning of 'diluted to $1 \mathrm{~L}$.' Analysis of their work suggested that this occurred because they thought the volume of the final solution would be $1.02 \mathrm{~L}$ rather than $1 \mathrm{~L}$. Only two students (12\%) failed to solve the problem. Of these, one of them correctly solved the second problem. All the students identified the kind of quantities the unknown and the data were and worked with the correct units. These findings suggest that all of the students but one (94\%) were able to use the model and construct the map. Therefore, it can reasonable be assumed that the students evaluated a model that they knew how to use.

For the second problem (calculate the density of a $1.79 \mathrm{M}$ and $18 \%$ by mass solution of $\mathrm{MgSO}_{4}$ ) only four students (24\%) solved it correctly. An example of student work is shown in Figure 5. Seven students (41\%) solved the problem partially. Two failed to solve the problem completely because they did not use the concept of concentration as percentage mass, and five because they expressed the concentration of the solution in $\mathrm{g} / \mathrm{L}$ instead of molarity. This meant that the students related the solution concentration to volume of solution and mass of solute, rather than moles of solute. This is a common misconception reported in the literature (see, e.g., Heyworth, 1999) and shows why it is so important to identify and work on quantities rather than values for these quantities. However, when the concentration is expressed in units $(\mathrm{mol} / \mathrm{L})$ instead of using the symbol $\mathrm{M}$, all the students were able to identify the relationship between molarity, mole of solute and volume of solution as they did in problem one. Two of the students were unable to solve the problem making a lot of mistakes and three students did not write any answer.

\section{Student Evaluation of the Heuristic}

Evaluation of student perception of the value of the problem-solving heuristic was by means of a self-completion questionnaire. In this the students were asked 11 questions that sought their views as to whether or not the heuristic was of value to them in enhancing problem-solving skills, if so which parts helped, and if not why not. The student responses to each question are now described in turn. 


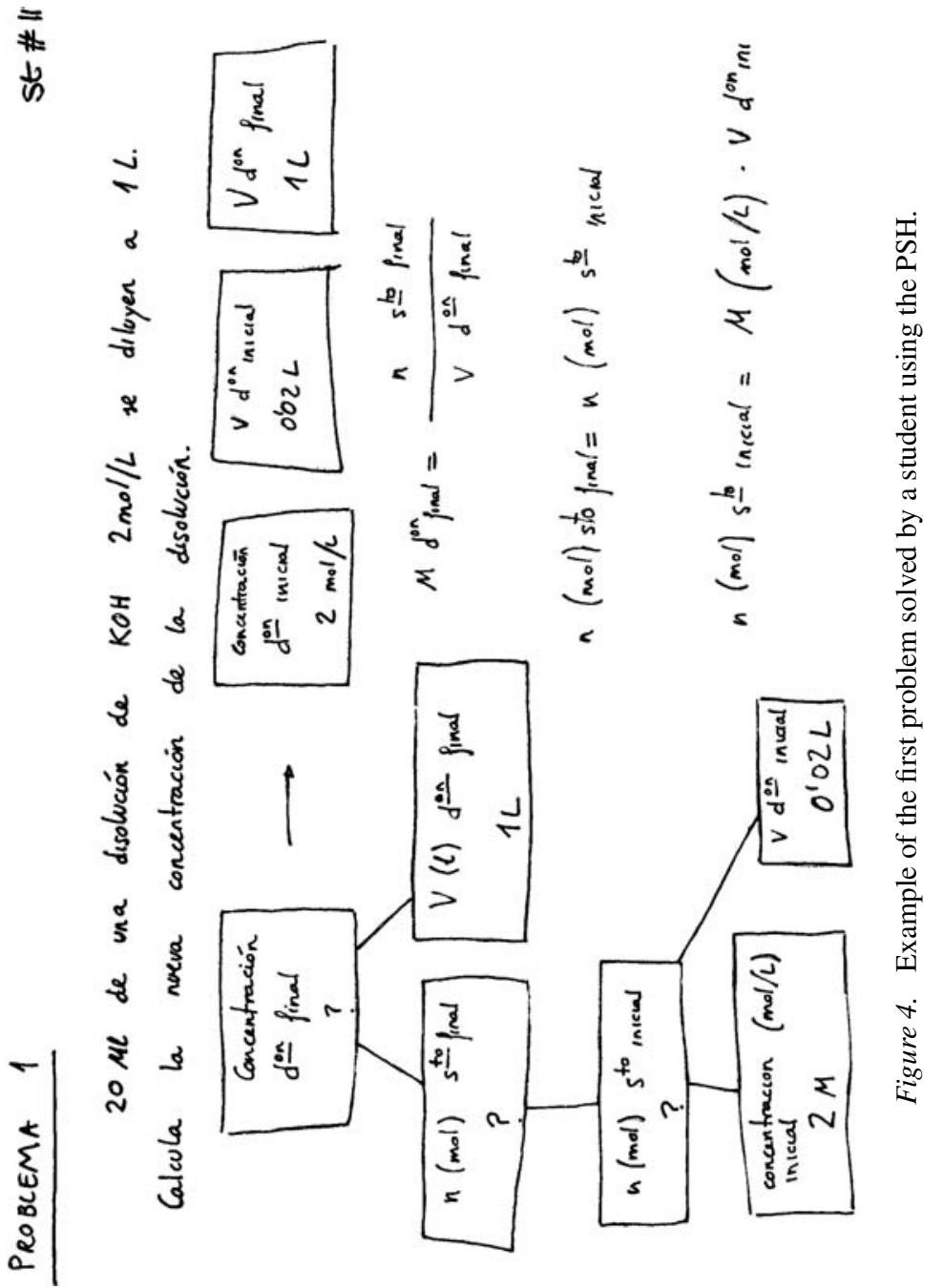




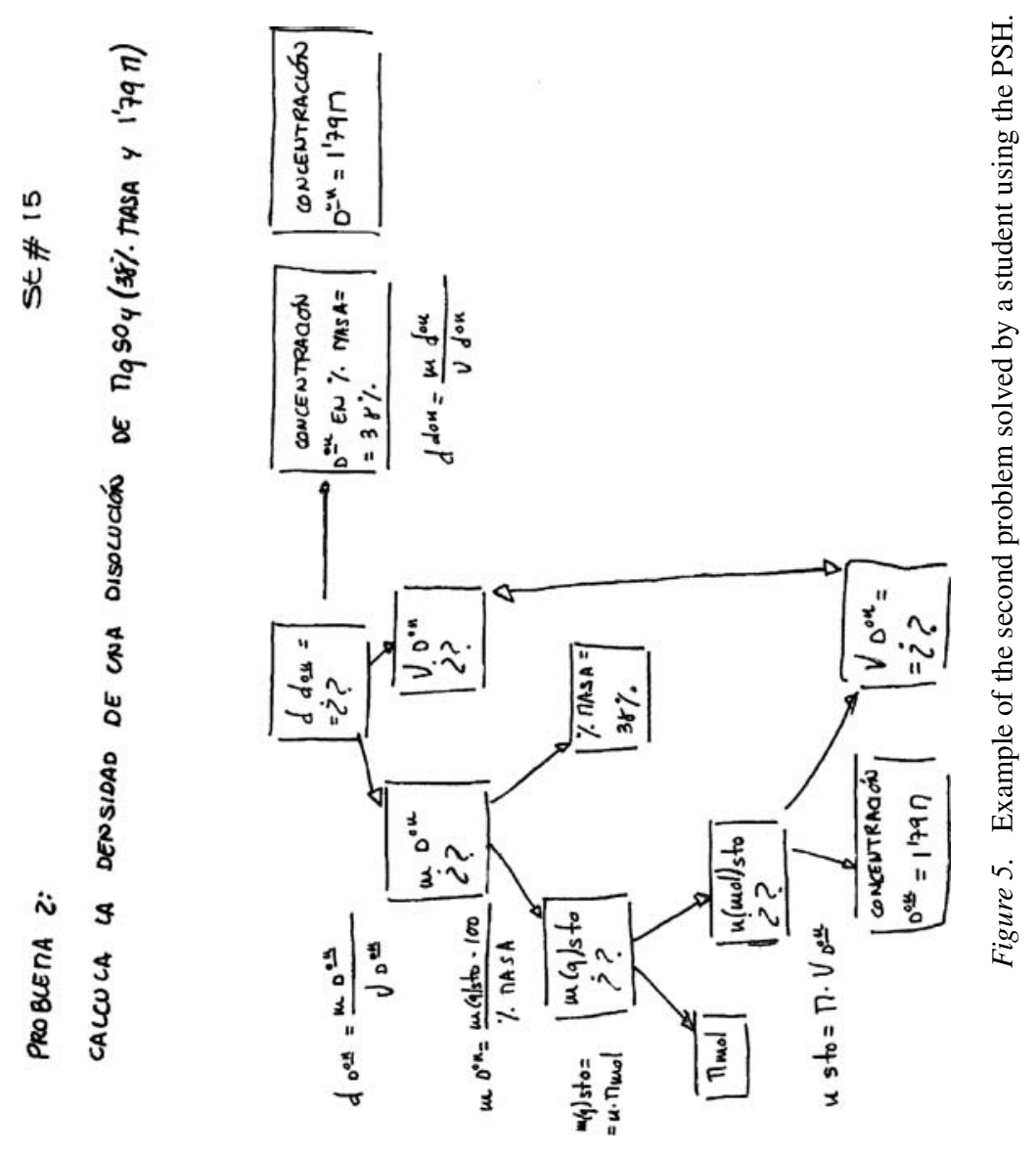


The first question asked if the students understood the steps involved in the problem-solving process using the heuristic. Most students $(14,82 \%)$ gave a positive answer. Only a few provided explanations for their answers, some of which are presented below:

"I think that in making a map you have to solve the problem backwards, from the unknown to the data" (student 6).

"It is well explained and it can be perfectly understood" (student 11).

Two students (12\%) said they did not understand the problem-solving process and argued that:

"It is more difficult to make the map than to make the problem" (student 10) and

"When I break the problem into parts I got more unknowns" (student 4).

One student (6\%) who gave both answers (yes and no) has not been included in the above categories.

It seems that for student 4 , it is not clear that the purpose of breaking a problem into steps is to divide the whole problem into sub-problems until all the new unknowns are known. This way, as the student intimated, more unknowns are found but once the map is made, the values for all the unknowns are reached working forwards.

In question two of the questionnaire, students were asked which steps they found most useful to solve a problem. Figure 6 shows the students' answers to this question. The steps most useful for students to solve a problem, along with student feedback, were the following:

Step 1: Read the problem carefully (71\%), as student 1 said: "It helps to understand the details."

Step 4: Identify the unknown and the data (65\%), for student 5 "without this step I think it is impossible to do the problem well."

Step 3: Identify what the problem is about (53\%). Student 1 argued: "This way you can discard wrong formulae."

Step 6: Express all the quantities in the same unit system (47\%), for student 2 "It is the one in which you can easily be wrong."

Step 11: Check if the answer is reasonable (47\%).

Step 5: Determine what kind of quantity are the unknown and the data $(41 \%)$.

Step 9: Break the problem into parts (41\%). For student 1 "This way you discover the problem better and more quickly" and for student 10 "once you have read the problem you have to break it into parts because it (the problem) cannot be done at once."

Step 10: Apply the calculations (41\%). 


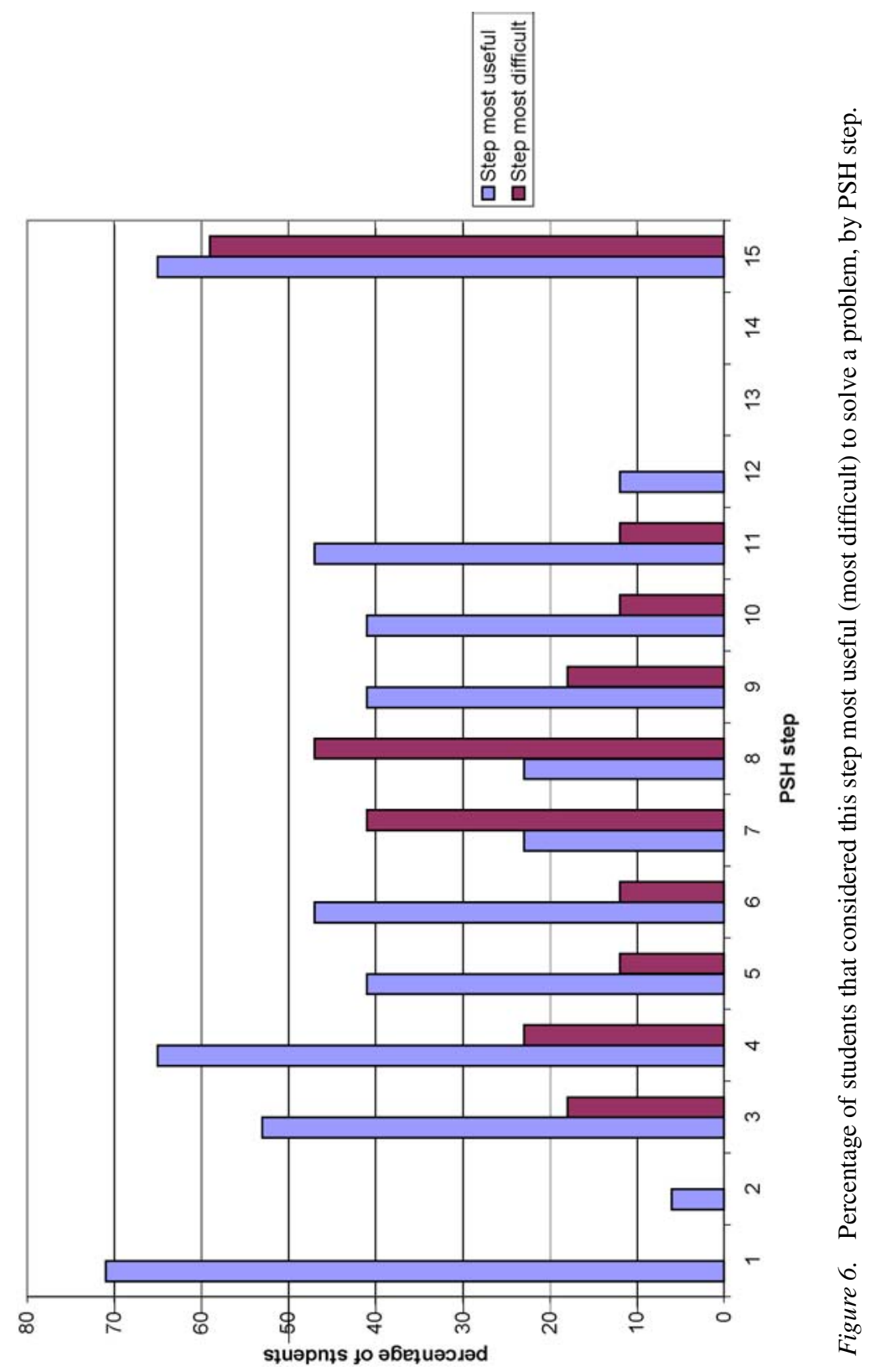


As step 9 is part of step 8, because while you are doing the 'map' you are already breaking the problem into parts, both steps can be considered simultaneously as the planning stage of the problem-solving process. Therefore, 11 students (65\%, Figure 6 - step 15) considered the planning stage one of the most useful parts of the problem-solving process.

In summary, based on the students' responses to the questionnaire it seems that the most useful steps are related to the understanding stage (steps 1 and 3-5) and the planning stage (steps 8 and 9), with the verification stage (step 11) and the 'carry out the plan' stage (steps 6 and 10) next.

According to the students the less useful steps were step 2 (look up in textbook or dictionary the meaning of the words you do not know in the problem statement) and step 12 (write down the ideas you have learnt in doing this problem). For step 2, this may be because the students felt that they already knew the meaning of all the words that appeared in the problem statements during the evaluation. To emphasize the importance of this step for problem-solving, it would thus be helpful to use at least one word problem when introducing the PSH and include some words in the statement which were unfamiliar to the students.

Based on the student responses step 12 appears to be the least useful. This may be because most students are not aware that one purpose of doing a problem is to increase the problem solvers knowledge. As mentioned above, students and indeed many teachers tend to focus on producing correct numerical answers. Such a view may make the students feel that the aim of doing problems is to assess the student knowledge rather than to help them increase their knowledge about science. The use of external summative examination probably exacerbates such views (see Vulliamy, 1990).

In question three, students were asked which steps they found most difficult in solving a problem. Figure 6 suggests that the students consider step 8 (make a map that relates the unknown with the data, 47\%) as the most difficult to solve a problem, followed by step 7 (organize the information in the problem statement using a representation, 41\%). Once again if we consider together steps 8 and 9, for 10 students (59\%, Figure 6 - step 15) the most difficult stage in the problem solving process is the one related to planning, where the solver has to look for a pathway to solve the problem in a conceptual way. The student's answers (see quotes below) suggest that the difficulty for them is mainly due to two reasons:

(a) They have to look for the relationship between the different quantities involved in the problem solution, as some students wrote: "because it is necessary to relate formulae to make the map to find out the 
solution" (student 8) and "because you have to look for a relationship between the unknown and the data and this is very time consuming" (student 17) and

(b) It is difficult for them to think backwards. In other words, to use the logic reasoning involved in the planning strategy needed to solve a problem, as student 16 wrote: "If you do not have imagination it is difficult to solve a problem backwards."

Comparing the number of students that chose both steps 8 and 9 in questions 2 and 3, it seems that these steps are considered the most difficult, but interestingly also the most useful in solving problems. This in fact makes sense because it is in these steps where students actually have to produce an external qualitative representation of the problem solution, and then apply this to their calculations.

The fourth question asked if the students thought any other steps were needed to solve a problem. All the students reported that they felt no other steps were needed to solve a problem. Student 11 explained his answer as follows: "No, because It is perfectly explained and the steps are the needed ones." Student 1 expressed that "these steps were more than enough."

The fifth question asked if the students followed the order of the steps. All the students reported that they did indeed followed the step order, but one commented that he omitted some steps.

The sixth question asked if the students felt that they had learnt how to solve a problem using the heuristic: the student responses varied. All but one of the students (94\%) (whose answer was difficult to interpret), felt that they had gained new learning about the problem-solving process as seen in the following quotes:

"To analyze and break the problem into parts and to see what part is related with another one" (student 3).

"To order the data, to identify the data and to relate them easier" (student 15).

"To solve easily (problems) through the map that relates the (new) unknowns" (student 6).

"I have learnt how to clarify data and to look for the unknowns" (student 4).

"It is useful to have a scheme to see what the problem is about" (student 16).

"I have learnt that with this model you order the formulae in a easy and good way. In addition it is easy to follow it" (student 1).

"To develop some steps to solve the problem" (student 8).

"That there are a lot of methods to solve it and to check that the solution is correct" (student 13). 
The first five answers were the most frequent ones, and all are needed and related to solve the problem in a conceptual way.

The students also commented that they found it easy to follow the model. For example, student 5 explained that "it is easier and I think you cannot make mistakes (using the PS model). In another way, it can be done more quickly (to solve the problem) but, maybe, you can make mistakes with stupid things and have everything wrong" and student 9 explained the need to get used to the model to get good results "... this model helps a lot, but you have to get used to it."

The seventh question asked if the students thought this model could help them to cope with problems. Student 10's response was "maybe," but the remainder agreed that the PSH helped them to cope with solving the problems. The answers given by the students included the following explanations:

- The problems can be solved easily with this model;

- It helps more with the difficult problems than with the easy ones, because the organization is very useful and for the easy problems it is a little boring;

- It makes you avoid mistakes, especially when you have to use many formulae;

- It is easier how to begin to solve a problem;

- It is easier to find out the unknowns and to relate them with the formulae.

The eighth question asked if the students felt more positive about tackling new problems using this model: the answers were varied. Eleven students $(65 \%)$ were positive, five students (29\%) gave a negative answer to this question, and one student (6\%) showed some doubt in his answer, writing: "maybe not, because of the time needed to solve the problem" (student 11).

The reasons given by the students who were less positive about the use of the heuristic suggested that they felt that they already had their own methods and preferred these methods reporting that they found the heuristic too complicated. Student 9 argued "It is easier for me (to solve the problems) using this model but, at the moment, I do not feel confident." This student also said in questions 6 and 7 "... this model helps you a lot, but you have to get used to it." From these answers it seems that in order to increase the confidence of the students as problem solvers using this model, they need to use it for a longer period of time in order to become more familiar with the more generic means of addressing problems.

Students that were positive about tackling new problems using the heuristic attributed their increase in confidence to the following reasons: 
- You can show your ideas and see if the problem if solved or not before doing mathematical calculations;

- It helps you with how to begin to solve a problem;

- It is more difficult to make mistakes using this model;

- The model is very structured.

The ninth question asked if the students would recommend this model to a friend. Most of the students $(13,77 \%)$ responded positively answer because in their opinion the model is an efficient, good, useful model that is easy to use. For example, student 1 specified that "it also gives you confidence about the answer and learning." Two students might recommend the heuristic but indicated that this would depend on the level of difficulty of the problem. One student commented that he/she already knows well how to solve problems.

Again some students saw this model very useful when you have to cope with a real problem instead of an exercise.

In question ten, the students were asked why they felt that they had not solved the problem (if they have failed). Potential answers included, because they did not understand the scientific concepts related to the problem or the problem-solving process. Almost half the students $(7,41 \%)$ did not answer this question. Four students (24\%) commented that they did not solve the problem because of the scientific concepts related to the problem, as student 11 wrote: "If I have not solved the problem it is because of the concepts involved in it." For five students (29\%), it was due to the problem-solving process, and one student (6\%) gave both answers.

The final question asked if the students thought this model helped them to know when they had to assume an arbitrary value for a given quantity to solve a problem. Most of the students $(13,76 \%)$ gave a positive answer to this question. Student 2 explained his agreement as: "because if you have two unknown that are the same you can take an arbitrary value (the same for both to solve the problem)." The rest of the students did not answer the question.

\section{Discussion AND IMPLiCATIONS FOR TEACHING USING A PROBLEM SOLVING HEURISTIC}

Several issues arise from this study, including the potential value of the PSH as a metacognitive and a cognitive tool.

According to the findings in problems 1 and 2, the map was well constructed for $94 \%$ of the students, so there is reason to believe that these students were evaluating a heuristic they knew how to use. Difficulties in 
solving problem 2 can be attributed to some student alternative conceptions and a weakness in mastering some of the concepts involved in the problem. Although five students said they could be wrong because of the problemsolving process, all of them correctly solved the first problem and one student solved both problems. Two students misunderstood the concept of molarity instead expressing concentration in $\mathrm{gL}^{-1}$ and the other two students did not hand in the second problem. It seems, then, that the difficulty in solving the problem for four students was again a lack of content knowledge about the solutions. This is probably due to the relative limited chemistry background of the students involved in this study.

According to the student evaluation the most useful steps for the heuristic are related to the understanding and planning stages, whereas the learning stage is seen as less important. The most difficult stage also is the planning stage, because as the students commented they had to work backwards and look for relationships between different quantities, meaning they had to use their domain knowledge. This is consistent with the above findings and with the students' limited chemistry background. It is not especially surprising that the planning stage is considered both the most useful and at the same time the most difficult. It is at this stage when students actually have to solve the problem, by developing a qualitative representation working at the microscopic level and by looking for relationships between concepts.

Almost all of the students (94\%) felt that they gained knowledge about the problem-solving process, especially about cognitive activities such as: breaking the problem into parts; clarifying and organizing data; seeing relationships between the data and the unknown; looking for new unknowns; and, devising a scheme to see what the problem is about. These activities are essential if students (like experts) are to make a qualitative representation of the problem - the main difference found between experts and novices in problem-solving performance. The PSH, by guiding students in the qualitative reasoning used by experts, is intended to increase the students' problem-solving abilities. Therefore, this approach can be considered as a metacognitive tool because it improves students' problem-solving process knowledge and at the same time acts as a cognitive tool because the model scaffolds students in a systematic way focusing more on conceptual reasoning than on solving problems by conducting calculations.

Some $94 \%$ of the students considered that the heuristic helped them to cope with problem-solving. Some advantages students attributed to the PSH were: reducing the chance of error especially when a lot of formulae are involved; helping to begin to solve a problem; helping to show ideas and see if the problem is solved or not before doing mathematical calcula- 
tions; and, ease in finding out unknowns and in relating them with formulae or ideas. Breaking the problem into parts allows students to focus on a few ideas at a time, when they have to work on a new unknown, which means that the likelihood of making mistakes should decrease. The map format permits students to check easily all the relationships between concepts and ideas before engaging in calculations. The PSH helps students systematically in that it helps them to engage in logical reasoning to get a qualitative description of the problem using a backwards strategy as suggested by Heyworth (1999).

Another advantage of the PSH seen by students is they can more easily realize when they have to assume an arbitrary value for a given quantity (Figure 5). Their positive feelings about the heuristic are supported by the finding that most students (76\%) would recommend this model to a friend because in their opinions it is both efficient and useful.

The students felt that the PSH would be an effective means of solving more complex problems than exercises, but for easy problems it is seen as too complex and time consuming. This is similar to the findings of McCalla (2003) and is logical in that, as Kramers-Pals et al. (1983) point out, working forwards is an efficient strategy and saves time when the problem is familiar. A forwards strategy can be applied when the relationship between the unknown and the data are known, even when the ideas or formula that are related with the solution problem are not very complex and the working memory can manage to process all this information. In contrast when the number of ideas in the formulae overwhelm the working memory, the construction of a map helps both in the reasoning qualitative process and in supporting the working memory by serving as a external memory (McCalla, 2003). Although many of the students $(11,65 \%)$ were positive about tackling new problems using the $\mathrm{PSH}$, an increase in confidence it would be likely when using the model for a longer period of time as expressed by some of the participants.

The map structure permits easy visualization of the solution to the problem and helps students to see where they fail, as was found in problem 2 where students evidenced inaccurate knowledge about the concept concentration when expressed in percentage by mass and an alternative conception about the molarity concept. In addition, this model can help overcome such problems because the use of this graphical method allows teachers to correct mistakes because it is easy to work on the conceptual relationships between the quantities involve in the problem solving which would increase the students' conceptual knowledge in a given domain. Therefore, the PSH can be used to both identify and overcome mistakes in problem-solving. 
Related to the above, this method has potential use for teachers as a formative assessment tool. The map permits teachers to observe student work and the teacher is then in a position to give feedback to the students at any stage of the process. The pathway may help teachers to detect student difficulties in solving problems (Ashmore, Frazer \& Cassey, 1979) and to understand the student's thinking patterns. In addition, it seems the PSH could be applied to cooperative learning because the model lends itself to problem-solving in group setting especially when using a graphical method. Students could, for example, use cards with magnets with the different quantities, this way they can construct a problem map and modify it very easily.

As this heuristic pays more attention to the qualitative solution of a problem than mathematical calculations (to arrive at a numerical solution), it may also help to decrease the 'gender gap' found in science by reducing anxiety about mathematics and increasing their conceptual understanding, some reasons which are claimed to affects girls' achievement and attitude towards science (Dalgety \& Coll, 2003; Kahle \& Meece, 1994; Zohar \& Sela, 2003).

\section{CONCLUSIONS}

This case study sought to devise a PSH based on constructivist views of learning and to evaluate its effectiveness. Due to the size (17 students) of the sample used in this study, any generalization of the conclusions needs to be treated with caution (see Merriam, 1988 for a detailed discussion of this issue). In studies such as is reported in this work, the author provides a detailed description of the work and provides an audit trail of the work enabling readers to see what impact or meaning the findings may have for their own educational context: a process referred to by Guba and Lincoln $(1989,1994)$ as transferability. Within this context the author provides what she sees as the main conclusion to be drawn from this work.

The high proportion of students in this study who expressed positive feelings about the benefits of the PSH, suggest that it is reasonable to believe that similar results can be obtained in a large scale study. These studies are planned to be done next academic year.

According to the students of this study the PSH achieved some degree of success because in their opinion it can contribute to improving each of the three aspects involve in the problem-solving task: domain content knowledge, procedural strategies and attitude. First, the PSH helps students to recognize relationships between concepts and to build more complex connections. From a constructivist point of view, this is very important 
because it helps students develop more complex cognitive structures and increases their content knowledge. Second, the map is an effective way to assist the qualitative reasoning involve in problem-solving. In addition it serves as an external representation of this reasoning. Finally, the above advantages of using the PSH may increase student confidence about tackling new problems because it provides students with the scaffolding needed to set up a problem. Students should see the PSH as a strategy that can be used when needed rather than as a mechanical lock-step procedure. The confidence of students in problem solving can be increased by using the model for a long period of time.

In addition, more studies should be done to increase the scope of its potential applications in the classroom as alluded to above: for example, in formative assessment, to identify and overcome alternative conceptions, problem-solving in a cooperative group learning environment, and as a instructional tool to decrease the gender gap in science.

\section{ACKNOWLEDGMENTS}

The author would like to express her gratitude to Assoc. Prof. Alister Jones, Assoc. Prof. Richard K. Coll, and the Center for Science and Technology Education Research of the University of Waikato, New Zealand for giving her the opportunity of being a visiting researcher from September 2002 to January 2003; and to the Consejeria de Educación de la Junta de Comunidades de Castilla-La Mancha (Spain) for its generous support during that time. Special thanks are due to Dr. Bronwen Cowie for her suggestions on the New Zealand study, and to the teachers and students in the school in New Zealand and Spain that made this research possible. Her deepest gratitude goes to Assoc. Prof. Richard K. Coll for his continuous and valuable help.

\section{REFERENCES}

Ashmore, A.D., Frazer, M.J. \& Cassey, R.J. (1979). Problem-solving and problem-solving networks in chemistry. Journal of Chemical Education, 56, 377-379.

Ausubel, D.P. (1968). Educational Psychology: A cognitive view. New York: Holt, Rinehart and Winston.

Ausubel, D.P. \& Robinson, P.G. (1971). School learning. New York: Holt, Rinehart and Winston.

Bodner, G.M. (1987). The role of algorithms in teaching problem solving. Journal of Chemical Education, 64, 513-514.

Dalgety, J. \& Coll, R.K. (2003). Development of chemistry attitudes and experiences questionnaire (CAEQ). Journal of Research in Science Teaching, 10, 649-668. 
Fensham, P., Gunstone, R. \& White, R. (1994). The content of science: A constructivist approach to its teaching and learning. London: Falmer Press.

Finegold, M. \& Mass, R. (1985). Differences in the process of solving physics problems between good physics problem solvers and poor physics problem solvers. Research in Science and Technological Education, 3, 59-67.

Gabel, D.L. \& Bunce, D.M. (1994). Research on problem solving: Chemistry. In D.L. Gabel (Ed.), Handbook of research on science teaching and learning: A project of the national science teachers association (pp. 301-326). New York: Macmillan.

Gagne, R.M. (1985). The conditions of learning, 4th edn. New York: Holt, Rinehart and Winston.

Guba, E.G. \& Lincoln, Y.S. (1989). Fourth generation evaluation. Newbury Park, CA: Sage.

Guba, E.G. \& Lincoln, Y.S. (1994). Competing paradigms in qualitative research. In N.K. Denzin \& Y.S. Lincoln (Eds.), Handbook of qualitative research (pp. 105-117). Thousand Oaks, CA: Sage.

Hand, B. \& Prain, V. (1995). Teaching and learning in science: The constructivist classroom. Sydney: Harcout Brace.

Hayes, J.R. (1981). The complete problem solver. Philadelphia: Franklin Institute Press.

Heyworth, R.M. (1999). Procedural and conceptual knowledge of expert and novice students for the solving of a basic problem in chemistry. International Journal of Science Education, 21, 195-211.

Kahle, J.B. \& Meece, J. (1994). Research on gender issues in the classroom. In D.L. Gabel (Ed.), Handbook of research on science teaching and learning: A project of the national science teachers association (pp. 542-557). New York: Macmillan.

Kempa, R.F. \& Nicholls, C.E. (1983). Problem-solving ability and cognitive structure: An exploratory investigation. European Joumal of Science Education, 5, 171-184.

Kramers-Pals, H., Lambrechts, J. \& Wolff, P.J. (1983). The transformation of quantitative problems to standard problems in general chemistry. European Journal of Science Education, 5, 275-287.

Kramers-Pals, H. \& Pilot, A. (1988). Solving quantitative problems: Guidelines for teaching derived from research. International Journal of Science Education, 10, 511-521.

Larkin, J.H. (1983). The role of problem representation in physics. In D. Gentner \& A.L. Stevens (Eds.), Mental models (pp. 75-98). Hillsdale, NJ: Lawrence Erlbaum.

Larkin, J. \& Reif, F. (1979). Understanding and teaching problem solving in physics. European Journal of Science Education, 7, 191-203.

Lee, L. \& Fensham, P.J. (1996). A general strategy for solving high school electrochemistry problems. Journal of Science Education, 18, 543-555.

Maloney, D.P. (1994). Research on problem solving: Physics. In D.L. Gabel (Ed.), Handbook of research on science teaching and learning: A project of the national science teachers association (pp. 327-354). New York: Macmillan.

McCalla, J. (2003). Problem solving with pathways. Journal of Chemical Education, 80, 92-98.

McMillan, C. \& Swadener, M. (1991). Novice use of qualitative versus quantitative problem solving in electrostatics. Journal of Research in Science Teaching, 28, 661-670.

Merriam, S.B. (1988). Case study research in education. San Francisco: Jossey-Bass.

Mettes, C.T.C.W., Pilot, A., Roossink, H. \& Kramers-Pals, H. (1980). Teaching and learning problem solving in science, part I: A general strategy. Journal of Chemical Education, 57, 882-885. 
Mettes, C.T.C.W., Pilot, A., Roossink, H. \& Kramers-Pals, H. (1981). Teaching and learning problem solving in science, part II: Learning problem solving in a thermodynamic course. Journal of Chemical Education, 58, 51-55.

Newell, A. \& Simon, H.A. (1972). Human Problem Solving. Englewood Cliffs, NJ: Prentice-Hall.

Polya, G. (1957). How to solve it. New York: Doubleday \& Company.

Reif, F. (1983). How can chemists teach problem solving? Journal of Chemical Education, 60, 948-953.

Simon, D.P. \& Simon, H.A. (1978). Individual differences in solving physics problems. In R. Siegler (Ed.), Children's thinking: What develops? (pp. 325-348). Hillsdale, NJ: Lawrence Erlbaum.

Vulliamy, G. (1990). The potential of qualitative educational research strategies in developing countries. In G. Vulliamy, K. Lewin \& D. Stephens (Eds.), Doing educational research in developing countries (pp. 7-27). London, UK: The Falmer Press.

Zohar, A. \& Sela, D. (2003). Physics, his physics: Gender issues in Israeli advanced placement physics classes. International Journal of Science Education, 25, 245-268.

I.E.S. "Universidad Laboral",

Avenida de La Mancha, $s / n$

02080, Albacete,

Spain

E-mail:lpm@universidadlaboral.com 